OPEN ACCESS

Edited by:

Mosaad A Abdel-Wahhab, National Research Centre, Egypt

Reviewed by: Yasser S. El-Sayed, Damanhour University, Egypt Ahmed Esmat Abdel Moneim,

Helwan University, Egypt Saad Hussin Alkahtani, King Saud University, Saudi Arabia Basiru Olaitan Ajiboye Afe Babalola University, Nigeria

${ }^{*}$ Correspondence:

Sabreen Ezzat Fad nourmallak@yahoo.com

tORCID:

Mohamed Aboubakr orcid.org/0000-0003-1719-4844

Ehab Yahya Abdelhiee orcid.org/0000-0002-2276-877X

Sabreen Ezzat Fadl orcid.org/0000-0001-5541-6159

Mohamed M. Abdel-Daim orcid.org/0000-0002-4341-2713

Specialty section:

This article was submitted to

Predictive Toxicology,

a section of the journal

Frontiers in Pharmacology

Received: 29 July 2020 Accepted: 09 September 2020 Published: 29 September 2020

Citation:

Elkomy A, Abdelhiee EY, Fadl SE, Emam MA, Gad FA-M, Sallam A, Alarifi S, Abdel-Daim MM and Aboubakr M (2020) L-Carnitine Mitigates Oxidative Stress and Disorganization of Cytoskeleton Intermediate Filaments in Cisplatin-Induced HepatoRenal Toxicity in Rats.

Front. Pharmacol. 11:574441. doi: 10.3389/fphar.2020.574441

\section{L-Carnitine Mitigates Oxidative Stress and Disorganization of Cytoskeleton Intermediate Filaments in Cisplatin-Induced Hepato-Renal Toxicity in Rats}

\author{
Ashraf Elkomy ${ }^{1}$, Ehab Yahya Abdelhiee ${ }^{2 \dagger}$, Sabreen Ezzat Fadl ${ }^{3 *}$, \\ Mahmoud Abdelghaffar Emam ${ }^{4}$, Fatma Abdel-Monem Gad ${ }^{5}$, Adham Sallam ${ }^{1}$, \\ Saud Alarifi ${ }^{6}$, Mohamed M. Abdel-Daim ${ }^{6,7 \dagger}$ and Mohamed Aboubakr ${ }^{1 \dagger}$ \\ ${ }^{1}$ Department of Pharmacology, Faculty of Veterinary Medicine, Benha University, Toukh, Egypt, ${ }^{2}$ Department of Forensic \\ Medicine and Toxicology, Faculty of Veterinary Medicine, Matrouh University, Matrouh, Egypt, ${ }^{3}$ Department of Biochemistry, \\ Faculty of Veterinary Medicine, Matrouh University, Matrouh, Egypt, ${ }^{4}$ Department of Histology, Faculty of Veterinary \\ Medicine, Benha University, Toukh, Egypt, ${ }^{5}$ Department of Clinical Pathology, Faculty of Veterinary Medicine, Benha \\ University, Toukh, Egypt, ${ }^{6}$ Department of Zoology, College of Science, King Saud University, Riyadh, Saudi Arabia, \\ ${ }^{7}$ Department of Pharmacology, Faculty of Veterinary Medicine, Suez Canal University, Ismailia, Egypt
}

Cisplatin (CP) is one of the most active medications in cancer treatment and has some adverse effects such as hepatotoxicity and nephrotoxicity. The present research was planned to determine the protective effects of L-carnitine (LC) against CP-induced hepatorenal oxidative stress in rats, via investigating of some serum biochemical and tissue oxidative/antioxidant parameters, histological alterations, and immunohistochemical expressions of two different intermediate filaments (IFs) proteins; vimentin (VIM) and cytokeratin 18 (CK18). Twenty-eight rats were divided into four groups (7 rats each). Groups I and II were orally administered saline and LC (100 mg/kg body weight), respectively, once daily for 30 consecutive days. Group III received saline orally once daily and a single dose of CP on the 27th day of the experiment $[7.5 \mathrm{mg} / \mathrm{kg}$, intraperitoneal (IP)]. Group IV received both LC and CP. Injection of CP significantly $(P \leq 0.05)$ increased serum alanine aminotransferase (ALT), aspartate aminotransferase (AST), and alkaline phosphatase (ALP) activities and creatinine and urea levels, while serum total protein, albumin, and globulin concentrations significantly $(P \leq 0.05)$ decreased. In addition, CP induced a dramatic increase in the Malondialdehyde (MDA) level along with a substantial decrease in reduced glutathione (GSH) and catalase (CAT) in the hepato-renal tissues. Histologically, both liver and kidney of the $\mathrm{CP}$ treated group revealed marked degenerative changes. Moreover, overexpression of both VIM and CK18 in hepato-renal tissues were noted after CP injection. On the other hand, the administration of LC in the CP injected group (Group IV) restored the biochemical parameters, histological, and immunohistochemical pictures toward the normalcy. In conclusion, LC may be supplemented for chemotherapy with CP to ameliorate its oxidative stress and restore 
the normal organization of IFs, especially VIM and CK18 within the CP intoxicated hepatorenal cells.

Keywords: cisplatin, L-carnitine, hepato-renal toxicity, oxidative stress, intermediate filaments

\section{INTRODUCTION}

Under normal conditions, the various cell types of both liver and kidney have characteristic cytoskeleton and intermediate filaments (IFs) compositions, which are involved in the cell shape maintenance, mechanical stability, and intracellular organization and transport (Ku et al., 1999). Vimentin (VIM) is the IF of the non-epithelial cells, especially those of mesenchymal origin (Sen et al., 2010). The only IF protein found in the endothelial cells and fibroblasts (Evans, 1998). Meanwhile, cytokeratins (CKs) represent the largest and most common epithelial IFs (Snider, 2016). Since chemotherapeutic drugs are metabolized by the liver and excreted through the kidneys, hepato-renal toxicity is a common adverse effect caused by chemotherapy (Abuzinadah and Ahmad, 2020).

Although cisplatin (CP) [cis-diamminedichloroplatinum (II), CDDP], is potent anticancer medication use to treat a variety of tumors including testicular, ovarian, bladder, and lung (Ibrahim et al., 2016; Karwasra et al., 2016). Several recent studies recorded that the CP induces hepatotoxicity (Abdellatief et al., 2017; Qu et al., 2019; Abdel-Daim et al., 2020; Hwang et al., 2020) and nephrotoxicity (Abdel-Daim et al., 2017; Abdel-Razek et al., 2020; Abo-Elmaaty et al., 2020; Sadeghi et al., 2020). Miller et al. (2010) reported cisplatin interacts with nuclear and mitochondrial DNA leading to cytotoxicity. Moreover, inflammation, apoptosis, and oxidative stress were mentioned as the most relevant pathways for CP toxicity (Meng et al., 2017) as well as, disorganization of the IFs components of the cytoskeleton (Evans and Simpkins, 1998). In the last decades, VIM is considered a mesenchymal marker for liver and kidney toxicity (Matos et al., 2007; Wang et al., 2017). Moreover, CKs are known as cellular stress protein, specially CK18, which use as novel markers of the liver and kidney injuries (Yang et al., 2015; Djudjaj et al., 2016).

L-carnitine (LC) is a natural nutrient, which synthesis from lysine and methionine essential amino acids. It is derived from dietary sources (75\%) and endogenous biosynthesis (25\%), mainly in the liver and kidney (Bremer, 1983; Aboubakr et al., 2020). LC is necessary for the production of ATP by $\beta$-oxidation of fatty acids in mitochondria (Furuno et al., 2001). Therefore, LC can prevent mitochondrial oxidative stress induces mitochondria damage and apoptosis in different cell types (Barhwal et al., 2007). The major regulatory role of LC in antioxidant processes was discussed in various organs like heart, colon, retina, and brain (Al-Majed et al., 2006; Cetinkaya et al., 2006; Sezen et al., 2008).

From all the above-mentioned data, the purpose of this research was to investigate the protective effects of LC administration on $\mathrm{CP}$-induced hepato-renal injuries in rats via investigating some serum biochemical and tissue oxidative/ antioxidant parameters. In addition, both histological alterations and immunohistochemical expressions of VIM and CK18 proteins were evaluated in all experimental groups.

\section{MATERIALS AND METHODS}

\section{Chemicals}

Cisplatin was obtained from (EIMC United Pharmaceuticals, Egypt). Each vial $(50 \mathrm{mg} / 50 \mathrm{ml})$ was dissolved in physiological saline ( $0.9 \%$ sodium chloride). LC was obtained from MEPACO Company (Inshas Elraml, Egypt). N-ethylmaleimide was obtained from Sigma Al-drich Co., USA. All biochemical analysis kits were purchased from Biodiagnostics Company (Dokki, Giza, Egypt).

\section{Experimental Animals}

The present study was carried out on a total number of 28 white Albino male rats weighed $185 \pm 5.7$ g. Rats were obtained from the Laboratory Animal Center, Faculty of Veterinary Medicine, Benha University, Egypt. They were acclimatized for two weeks prior to the experiment. The experimental design of the present study was ethically approved by the Ethics Review Committee of the Faculty of Veterinary Medicine, Benha University, Egypt (Approval No. 20181120). All rats received standard laboratory balanced commercial diet and water ad libitum.

\section{Experimental Design}

In the present study, male albino rats were randomly assigned into 4 equal groups (7 rats each). Group I (control), was administered saline orally (the vehicle) once daily for 30 consecutive days. Group II was received LC $(100 \mathrm{mg} / \mathrm{kg}$ body weight), orally once daily for 30 consecutive days (Avsar et al., 2014). Group III was served as CP toxic control and received saline orally once daily and a single dose of $\mathrm{CP}$ on the $27^{\text {th }}$ day of the experiment (7.5 mg/kg, IP; Adeyemi et al., 2017). Group IV was received both LC and CP. The saline or LC was given orally at $10 \mathrm{AM}$ along the experimental period (30 days).

\section{Sampling}

After $24 \mathrm{~h}$ from the end of the experiment, rats were anesthetized by isoflurane. Blood samples from each rat were collected by puncturing retro-orbital plexus in sterilized dry centrifuge tubes and kept for $30 \mathrm{~min}$ at room temperature (RT) in a slanted position for blood coagulation before centrifugation at $1200 \times \mathrm{g}$ for $20 \mathrm{~min}$ to obtain serum. The serum was preserved at $-20^{\circ} \mathrm{C}$ until used for biochemical investigations. After blood collection, the animals of all groups were sacrificed by cervical decapitation then the liver and kidneys were excised from each rat and washed with physiological saline. Liver and heart tissues (1 g/sample) 
were collected in Eppendorf tubes and stored at $-80^{\circ} \mathrm{C}$ until used. A gram specimen of each tissue was homogenized in $5 \mathrm{ml}$ phosphate buffer $\mathrm{pH} 7.4$ using an electrical homogenizer and maintaining the sample on ice. After homogenization, Nethylmaleimide was added directly to prevent oxidation of GSH. Tissue homogenates were centrifuged at $1,200 \times \mathrm{g}$ for $20 \mathrm{~min}$ at $4^{\circ} \mathrm{C}$. The resulting supernatants were isolated and used in the assessment of the oxidative stress biomarkers in hepatic and renal tissues. Remaining liver and kidney tissues were immediately preserved in $10 \%$ neutral buffered formalin for $48 \mathrm{~h}$ for histological and immunohistochemical investigations. All rats (28) and remnants of samples were buried in the strict hygienically controlled properly constructed burial pit.

\section{Serum Biochemical Studies}

The activities of alanine aminotransferase (ALT), aspartate aminotransferase (AST) (Reitman and Frankel, 1957), and alkaline phosphatase (ALP) (Tietz et al., 1983) were determined in collected sera as markers for liver injury. While albumin and total protein were determined according to Doumas et al. (1971) and Doumas et al. (1981) as markers for liver function, meanwhile the serum globulin was calculated by the subtraction of albumin from total protein. In addition, the serum levels of urea and creatinine were determined according to Coulombe and Favreau (1963) and Bartels et al. (1972) to evaluate kidney function.

\section{Detection of Oxidative/Antioxidant Cascades}

To detect the oxidative/antioxidant cascades the following measurements were determined, reduced glutathione concentration (GSH; Sedlak and Lindsay, 1968), catalase (CAT; Aebi, 1984) activity, and concentration of malondialdehyde (MDA; Ohkawa et al., 1979) by using special diagnostic kits obtained from Bio diagnostic company, Egypt.

\section{Histological Examination}

Tissue specimens were taken from the liver and kidney of rats in different groups. Then, specimens were dehydrated in serial dilutions of alcohol, cleared in xylene and embedded in paraffin. Paraffin sections of 5 microns thickness were cut and collected on glass slides and stained by hematoxylin and eosin for histological examination (Bancroft et al., 2013).

\section{Immunohistochemical Studies}

Liver and kidney paraffin sections of 5 microns thickness were cut and collected on positively charged slides for immunohistochemical localization of VIM and CK18 using a streptavidin-biotin complex (ABC) method. After, dewaxing, rehydration, and blocking endogenous peroxidase activity, the sections were heated at $90^{\circ} \mathrm{C}$ with citrate buffer $\mathrm{pH} 6$ for $30 \mathrm{~min}$. Nonspecific staining was blocked $10 \%$ bovine serum albumin for $30 \mathrm{~min}$. The sections were then incubated with the primary antibodies (rabbit monoclonal anti-vimentin and anticytokeratin 18, Abcam, Boston, the USA at 1:200 dilution) for $1 \mathrm{~h}$ at RT. Next, sections were incubated with biotinylated donkey anti-mouse IgG (Abcam, Boston, USA) for $30 \mathrm{~min}$ at RT. The visualization of the immunoreactions was observed using a commercial $\mathrm{ABC}$ system recommended by the manufacturer (Santa Cruz Biotech, CA, USA). Then the slides were then subjected to diaminobenzene (DAB) as the chromogen and counterstained with hematoxylin. The VIM and CK18 staining in both hepatic and renal tissues of all examined rats were evaluated blindly. At least 5 random high-power fields were checked at a magnification of 400X using Leica DM3000 microscope. Staining features were scored semi-quantitatively according to Liu et al. (2007) as follow: negative (-), weak (+), moderate $(++)$, strong $(+++)$ for no stain, $<10 \%$ positive cells, $10-50 \%$ positive cells, and $>50 \%$ positive cells, respectively.

\section{Statistical Analysis}

Statistical analysis was performed using SPSS (Version 20.0; SPSS Inc., Chicago, IL, USA). The significant differences between groups were evaluated by one-way ANOVA using the Duncan test as a post hoc. Results were expressed as mean \pm SEM. $\mathrm{P}<0.05$ was considered significant.

\section{RESULTS}

\section{Serum Biochemical Analysis}

Cisplatin injection significantly $(P \leq 0.05)$ increased serum ALT, AST, and ALP activities compared with those in control rats. Similarly, CP significantly $(P \leq 0.05)$ increased the levels of creatinine and urea. Conversely, serum total protein, albumin, and globulin were significantly $(P \leq 0.05)$ decreased due to $\mathrm{CP}$ injection compared to that in control rats. LC administration with $\mathrm{CP}$ restored these parameters towards the normal values (Table 1).

\section{Hepatic and Renal Oxidative Damage Parameters}

In the present study, there was substantially increased in MDA level along with a dramatic decrease in GSH and CAT in the liver and kidney tissues of $\mathrm{CP}$-intoxicated rats. Meanwhile, $\mathrm{LC}+\mathrm{CP}$ administrated group revealed a decrease in MDA level along with elevations in GSH and CAT in hepatic and renal tissues compared with CP treated group (Table 2).

\section{Histological Observations}

Liver sections from control and LC treated rats exhibited normal hepatic histo-architecture. Hepatocytes organize in cords radiating from the central vein and separate by regular sinusoids (Figures 1A, B). Otherwise, CP treated rats revealed several histological changes like dilatation of the central vein and sinusoids, inflammatory cells aggregation, Kupffer cells proliferation (Figure 1C), swelling of hepatocytes, hydropic degeneration (Figure 1D), and fatty infiltration with signet ring appearance in some hepatocytes (Figure 1E). The liver section from $\mathrm{LC}+\mathrm{CP}$ treated rats represented almost normal hepatocytes and sinusoids, but mild congested central vein and no signs of fatty changes were noted (Figure 1F).

Kidney sections from both control and LC groups showed regular renal histo-architecture with normal renal corpuscles and renal tubules; proximal (PCT) and distal convoluted tubules (DCT) and collecting (CT) tubules (Figures 2A, B). In the $\mathrm{CP}$ 
TABLE 1 | Effect of CP and/or LC treatment on serum biochemical parameters in rats $(n=7)$.

\begin{tabular}{|c|c|c|c|c|}
\hline Parameters & Control & LC & CP & $L C+C P$ \\
\hline ALT (U/L) & $76.36 \pm 2.96^{c}$ & $69.74 \pm 1.95^{\mathrm{c}}$ & $192.46 \pm 2.58^{a}$ & $115.57 \pm 3.85^{b}$ \\
\hline AST (U/L) & $48.19 \pm 4.39^{C}$ & $39.55 \pm 2.89^{c}$ & $107.64 \pm 3.72^{a}$ & $61.63 \pm 5.39^{b}$ \\
\hline ALP (U/L) & $122.97 \pm 3.91^{c}$ & $114.87 \pm 3.56^{c}$ & $252.01 \pm 8.49^{a}$ & $184.60 \pm 3.53^{b}$ \\
\hline T. protein $(\mathrm{g} / \mathrm{dl})$ & $8.03 \pm 0.06^{a}$ & $7.59 \pm 0.20^{a b}$ & $5.29 \pm 0.04^{c}$ & $7.17 \pm 0.28^{b}$ \\
\hline Albumin (g/dl) & $4.48 \pm 0.05^{\mathrm{a}}$ & $4.35 \pm 0.11^{a}$ & $3.14 \pm 0.04^{c}$ & $3.78 \pm 0.03^{b}$ \\
\hline Globulin (g/dl) & $3.54 \pm 0.10^{a}$ & $3.23 \pm 0.18^{a}$ & $2.15 \pm 0.04^{b}$ & $3.38 \pm 0.28^{a}$ \\
\hline Creatinine (mg/dl) & $0.64 \pm 0.01^{c}$ & $0.59 \pm 0.006^{c}$ & $1.22 \pm 0.05^{\mathrm{a}}$ & $0.88 \pm 0.01^{b}$ \\
\hline Urea (mg/dl) & $32.55 \pm 1.14^{\mathrm{C}}$ & $29.64 \pm 1.07^{c}$ & $78.03 \pm 2.99^{a}$ & $54.37 \pm 1.98^{b}$ \\
\hline
\end{tabular}

LC, L carnitine at dose of $100 \mathrm{mg} / \mathrm{Kg} P O ; C P$, cisplatin at dose of $7.5 \mathrm{mg} / \mathrm{Kg} I P$; AST, aspartate aminotransferase; ALT, alanine aminotransferase; ALP, alkaline phosphatase; T. protein, total protein.

Data are expressed as the mean \pm SE. Within each row, mean with different letters are significantly different at $p<0.05$.

TABLE 2 | Effect of CP and/or LC treatment on oxidative stress markers in liver and kidney tissues in rats $(\mathrm{n}=7)$.

\begin{tabular}{|c|c|c|c|c|c|}
\hline Parameters & Organ & Control & LC & $\mathrm{CP}$ & $\mathrm{LC}+\mathrm{CP}$ \\
\hline MDA (nmol/g) & Liver & $47.26 \pm 1.13^{\mathrm{C}}$ & $44.29 \pm 0.88^{c}$ & $116.34 \pm 3.17^{a}$ & $81.23 \pm 3.37^{b}$ \\
\hline $\mathrm{GSH}(\mathrm{mg} / \mathrm{g})$ & Liver & $69.28 \pm 2.09^{a}$ & $64.25 \pm 1.86^{a}$ & $34.81 \pm 2.25^{\mathrm{C}}$ & $54.34 \pm 2.17^{b}$ \\
\hline CAT (U/g) & Liver & $2.06 \pm 0.02^{\mathrm{a}}$ & $1.98 \pm 0.04^{a}$ & $1.06 \pm 0.04^{c}$ & $1.52 \pm 0.03^{b}$ \\
\hline MDA (nmol/g) & Kidney & $78.06 \pm 2.37^{\mathrm{C}}$ & $73.19 \pm 5.29^{c}$ & $182.06 \pm 5.16^{a}$ & $121.53 \pm 4.30^{b}$ \\
\hline $\mathrm{GSH}(\mathrm{mg} / \mathrm{g})$ & Kidney & $108.98 \pm 4.98^{a}$ & $101.61 \pm 3.47^{a}$ & $58.95 \pm 3.07^{c}$ & $78.65 \pm 1.85^{b}$ \\
\hline CAT $(\mathrm{U} / \mathrm{g})$ & Kidney & $2.43 \pm 0.05^{a}$ & $2.22 \pm 0.06^{b}$ & $1.06 \pm 0.04^{d}$ & $1.69 \pm 0.04^{c}$ \\
\hline
\end{tabular}

LC, L carnitine at dose of $100 \mathrm{mg} / \mathrm{Kg} P O ; \mathrm{CP}$, cisplatin at dose of $7.5 \mathrm{mg} / \mathrm{Kg} \mathrm{IP}$; MDA, malondialdehyde; GSH, reduced glutathione; CAT, catalase.

Data are expressed as the mean $\pm S E$. Within each row, mean with different letters are significantly different at $p<0.05$.

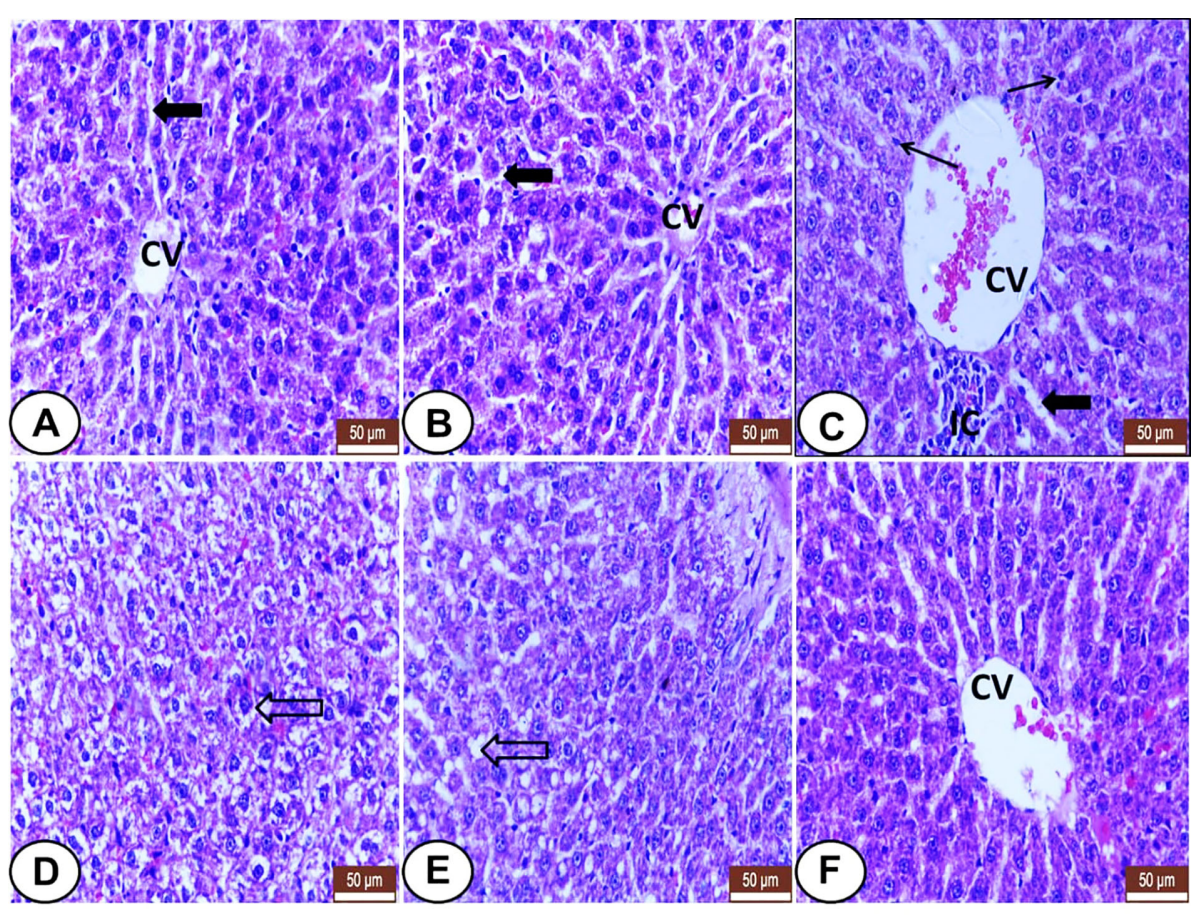

FIGURE 1 | Histological sections of livers from all examined groups. (A, B) Control and LC groups showed normal hepatic histo-architecture. Hepatocytes organized in cords radiating from central vein (CV) and separated by regular sinusoids (wide black arrow). (C-E) CP treated rats showed several histological changes. (C) showed dilatation of the central vein (CV) and sinusoids (wide black arrow), inflammatory cells aggregation (IC), and kupffer cells proliferation (thin arrow). (D) showed swelling of hepatocytes, hydropic degeneration (hollow arrow). (E) showed fatty infiltration with signet ring appearance in some hepatocytes (hollow arrow). (F) LC+CP treated rats showed almost normal hepatocytes and sinusoids, but congested central vein (CV), and no signs of fatty changes were noted. H\&E stain, scale bars $=50 \mu \mathrm{m}$. 
group, many distinguishing histological changes were noted including excessive degenerative changes and desquamation of the tubular epithelia were observed (Figures 2C-E) with the presence of eosinophilic hyaline casts in some tubules (Figures 2D, E). Also, deformity of some glomeruli with the widening of glomerular space was identified (Figure 2E) as well as congestion of peritubular blood vessels and capillaries (Figures 2C-E). However, the kidney from the $\mathrm{CP}+\mathrm{LC}$ group revealed mild tubular degeneration with minimal interstitial congestion (Figure 2F).

\section{Immunohistochemical Observations}

A summary of VIM and CK18 immunohistochemical expressions in the livers and kidneys of all examined groups was recorded (Tables 3, 4).

\section{VIM Expression}

Both control and LC rats expressed weakly to moderate VIM mainly in the hepatic sinusoids and Kupffer cells, but the hepatocytes were VIM negative (Figures 3A, B). Meanwhile, $\mathrm{CP}$-injected rats showed overexpression of VIM in the blood sinusoids (Figure 3C) and an increased number of Kupffer cells (Figures 3D, E) as well as some hepatocytes labeled weak VIM (Figure 3E). The LC+CP group showed moderate expression of sinusoidal VIM and fewer Kupffer cells (Figure 3F) compared with the CP group.

In kidneys, VIM was expressed mainly in the glomeruli, some peritubular blood capillaries, and interstitial fibroblasts of all experimental groups (Figure 4). In both control and LC groups, the renal tubules did not express VIM protein but, the interstitial tissues and glomeruli showed weak and moderate VIM staining,

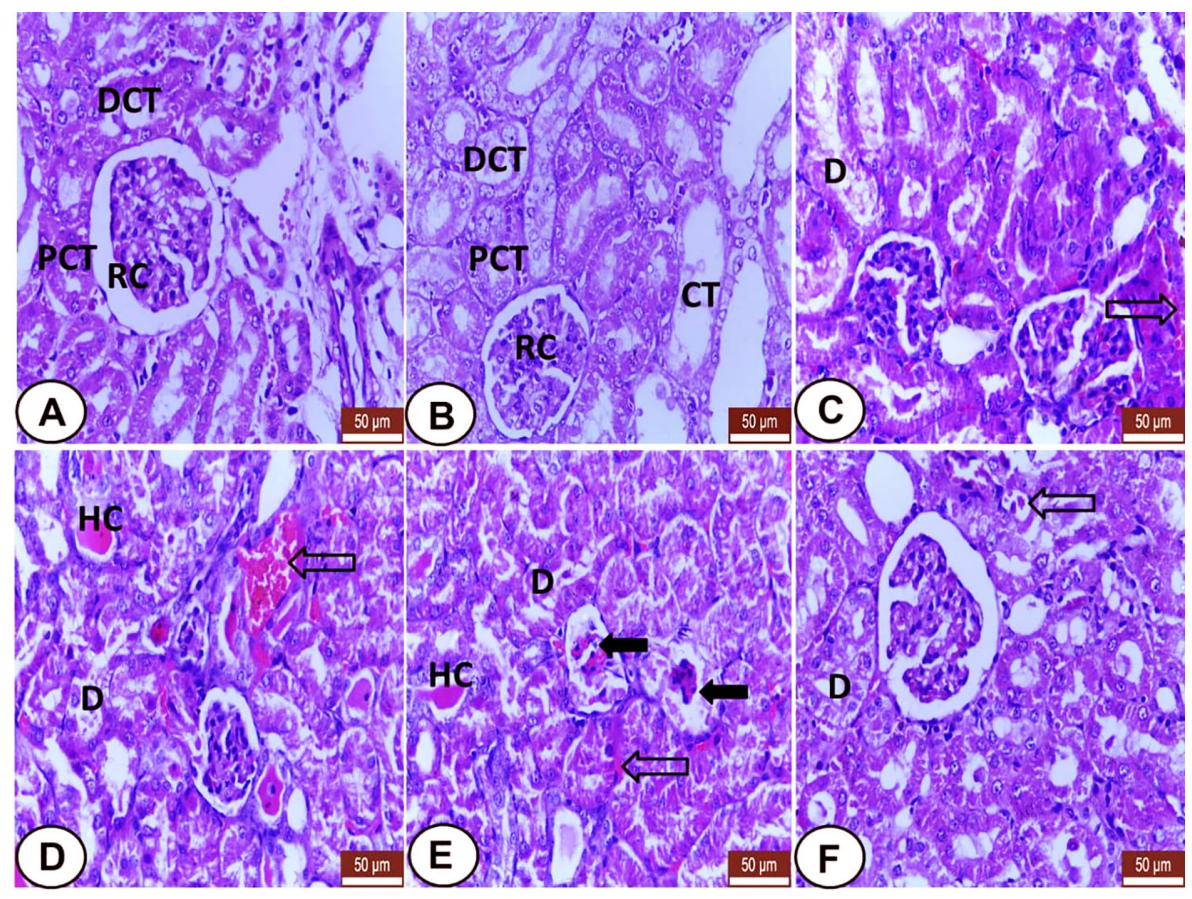

FIGURE 2 | Histological section of kidneys from all examined groups. (A, B) Control and LC groups showed regular renal histo-architecture with normal renal corpuscles (RC) and renal tubules; proximal (PCT) distal convoluted tubules (DCT) and collecting tubules (CT). (C-E) CP treated rats showed several histological changes. Degenerative changes and desquamation of the tubular epithelia (D), eosinophilic hyaline casts $(\mathrm{HC})$ in some tubules, deformity of some golumeruli with widening of glomerular space (wide black arrows) and congestion of peritubular blood vessels and capillaries (hollow arrows). (F) LC+CP treated rats showed mild degenerated tubular epithelium (D) with minimal interstitial congestion (hollow arrow). H\&E stain, scale bars $=50 \mu \mathrm{m}$.

TABLE 3 | Summary of VIM and CK18 immunohistochemical expressions in the livers of all examined groups.

\begin{tabular}{|c|c|c|c|c|c|c|c|c|}
\hline Hepatic tissues & \multicolumn{4}{|c|}{ VIM } & \multicolumn{4}{|c|}{ CK18 } \\
\hline Hepatocytes & - & - & + & - & + & + & +++ & ++ \\
\hline Kupffer cells & +/++ & $+/++$ & +++ & + & - & - & - & - \\
\hline
\end{tabular}

-, negative; +, weak; ++, moderate; +++, strong. 
TABLE 4 | Summary of VIM and CK18 immunohistochemical expressions in the kidneys of all examined groups.

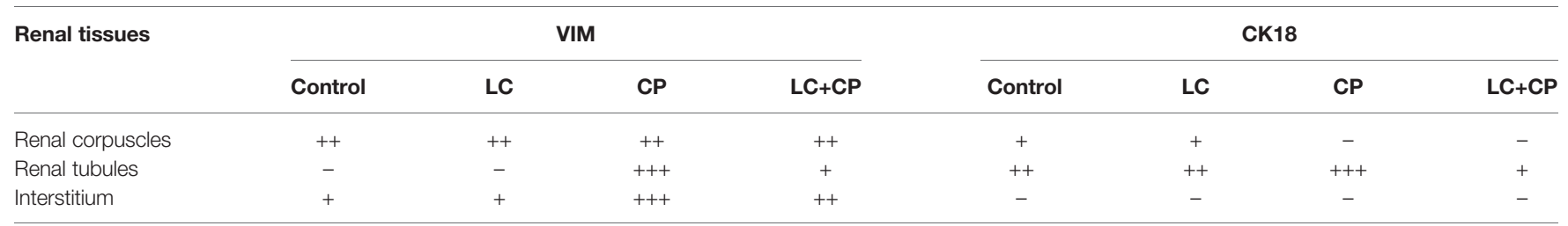

-, negative; +, weak; ++, moderate; +++, strong.

respectively (Figures 4A, B). Otherwise, overexpression of VIM was seen in the damaged renal tubules and interstitial tissues of the $\mathrm{CP}$ treated group (Figure 4C) that tended to be decreased in the interstitium and renal tubules of $\mathrm{LC}+\mathrm{CP}$ group compared with CP group (Figure 4D).

\section{CK18 Expression}

Hepatocytes of both control and LC rats showed weak CK18 staining at the periphery of the cells giving reticular appearance (Figures 5A, B). CP group revealed strong, dense, and clumped CK18 staining in the hepatocytes surrounding the central veins, fat cells, and triad area (Figures 5C-E). In addition, the LC+CP group showed lower CK18 immunostaining compared with the CP group (Figure 5F).

Regard to kidneys, both control and LC groups demonstrated weak to moderate CK18 immunostainings in the visceral cells layer of Bowman's capsule as well as the cells of different segments of renal tubules; PCT, DCT, and CT (Figures 6A, B). However, CK18 was overexpressed in the epithelial cells of renal tubules mainly PCT and few DCT after injection of CP (Figure 6C). Meanwhile, the LC+CP group showed a lower expression of CK18 (Figure 6D) compared with the $\mathrm{CP}$ group.

\section{DISCUSSION}

Hepatic and renal toxicity is the most common dose-limiting side effects of CP-induced chemotherapy (Neamatallah et al., 2018). Reducing the potential side effects of CP by LC can be helpful during chemotherapy. Elevated activities of liver enzymes are known to be markers of cellular leakage and loss of functional integrity of hepatocytes because they are released into the bloodstream when the hepatocyte plasma membrane is

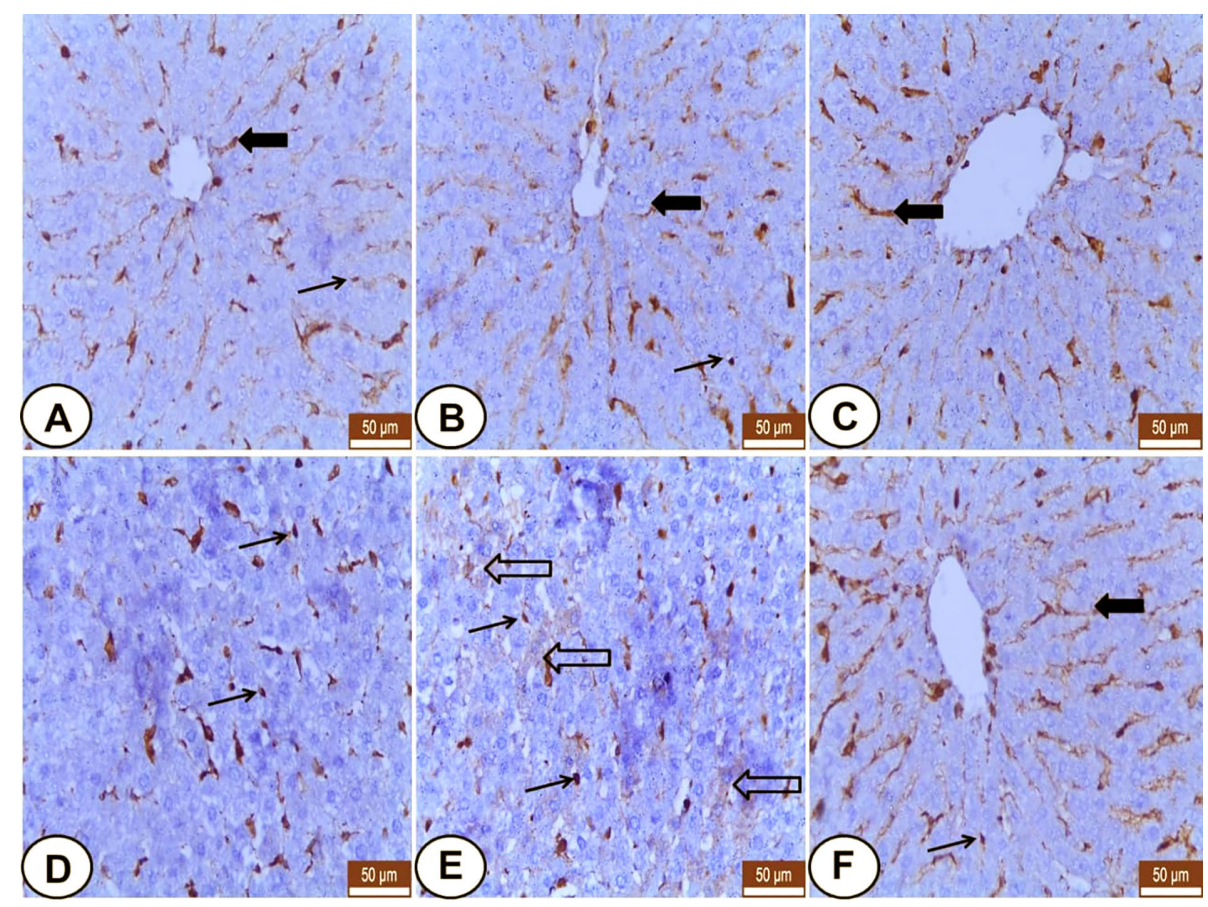

FIGURE 3 | Immunohistochemical staining of VIM in hepatic sections from all examined groups. (A, B) Control and LC groups showed weak to moderate hepatic sinusoids (wide arrow) and Kupffer cells (thin arrow) for VIM. (C-E) CP group revealed overexpression of VIM in blood sinusoids (wide arrow), Kupffer cells (thin arrows) and some hepatocytes showed weak VIM (hollow arrow). (F) LC+CP treated rats showed moderate expression of sinusoidal VIM (wide arrow) and fewer Kupffer cells (thin arrow) compared with CP group. Scale bars $=50 \mu \mathrm{m}$. 


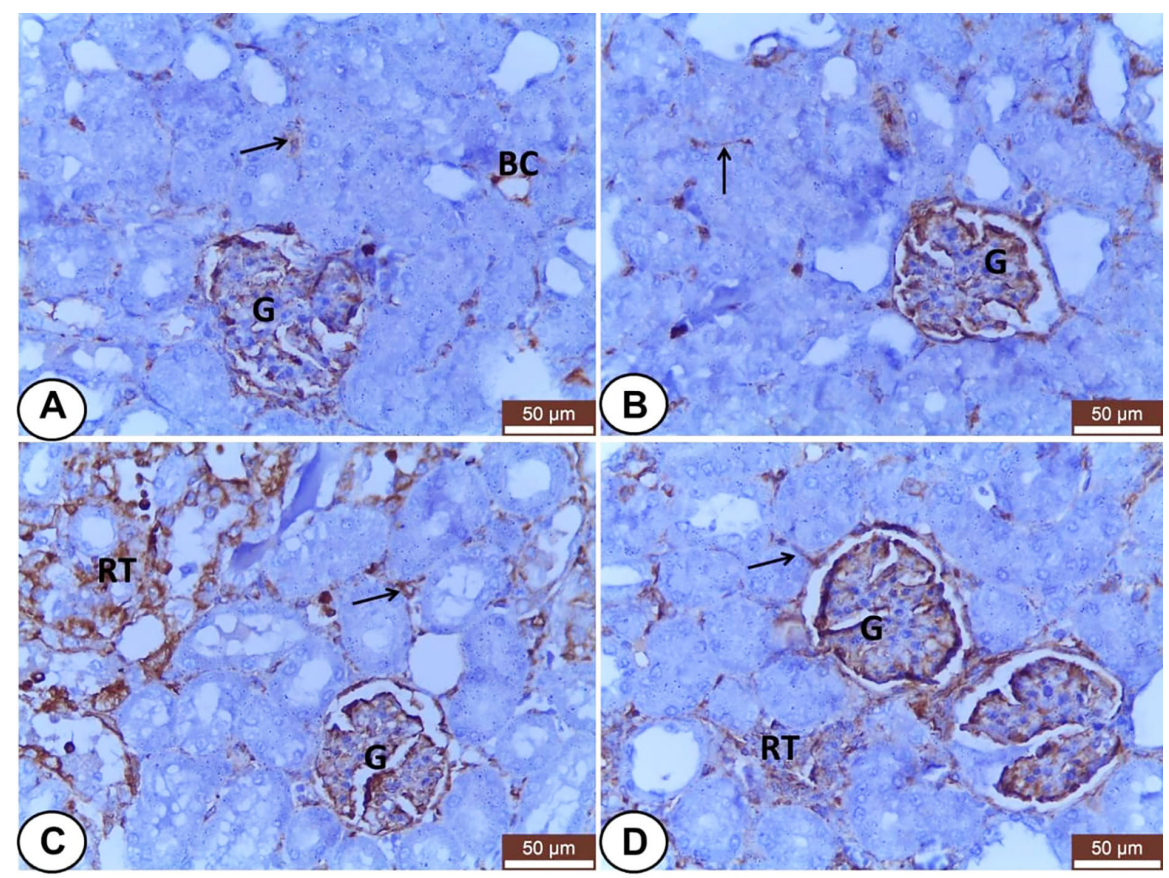

FIGURE 4 | Immunohistochemical staining of VIM in renal sections from all examined groups. (A, B) Control and LC groups showed weak to moderate VIM staining in the interstitial tissues (thin arrow), blood capillaries (BC), and glomeruli (G). (C) CP group revealed moderate glomerular (G) and strong tubular (RT) and interstitial (thin arrow) VIM staining. (D) LC+CP groups showed less VIM reactivity in comparison to CP group especially the interstitium (thin arrow) and renal tubules (RT). Scale bars $=50 \mu m$.

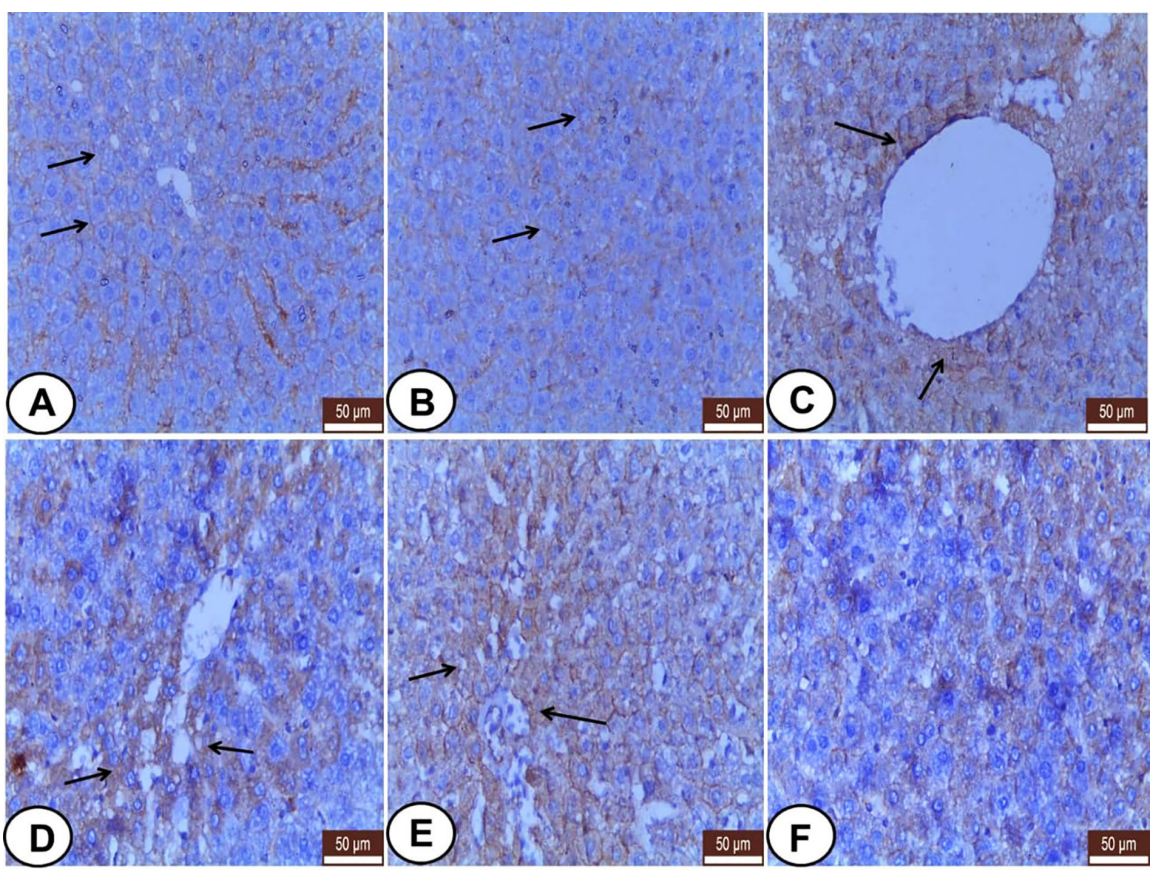

FIGURE 5 | Immunohistochemical staining of CK18 in hepatic sections from all examined groups. (A, B) Control and LC groups showed weak CK18 staining at the periphery of the hepatocytes in reticular pattern (thin arrows). (C-E) CP group revealed strong, dense, and clumped CK18 staining in hepatocytes surrounding the central veins (thin arrows), fat cells (thin arrows), and triad area (thin arrows). (F) LC+CP group showed less CK18 staining compared with $\mathrm{CP}$ group. Scale bars $=50 \mu \mathrm{m}$. 


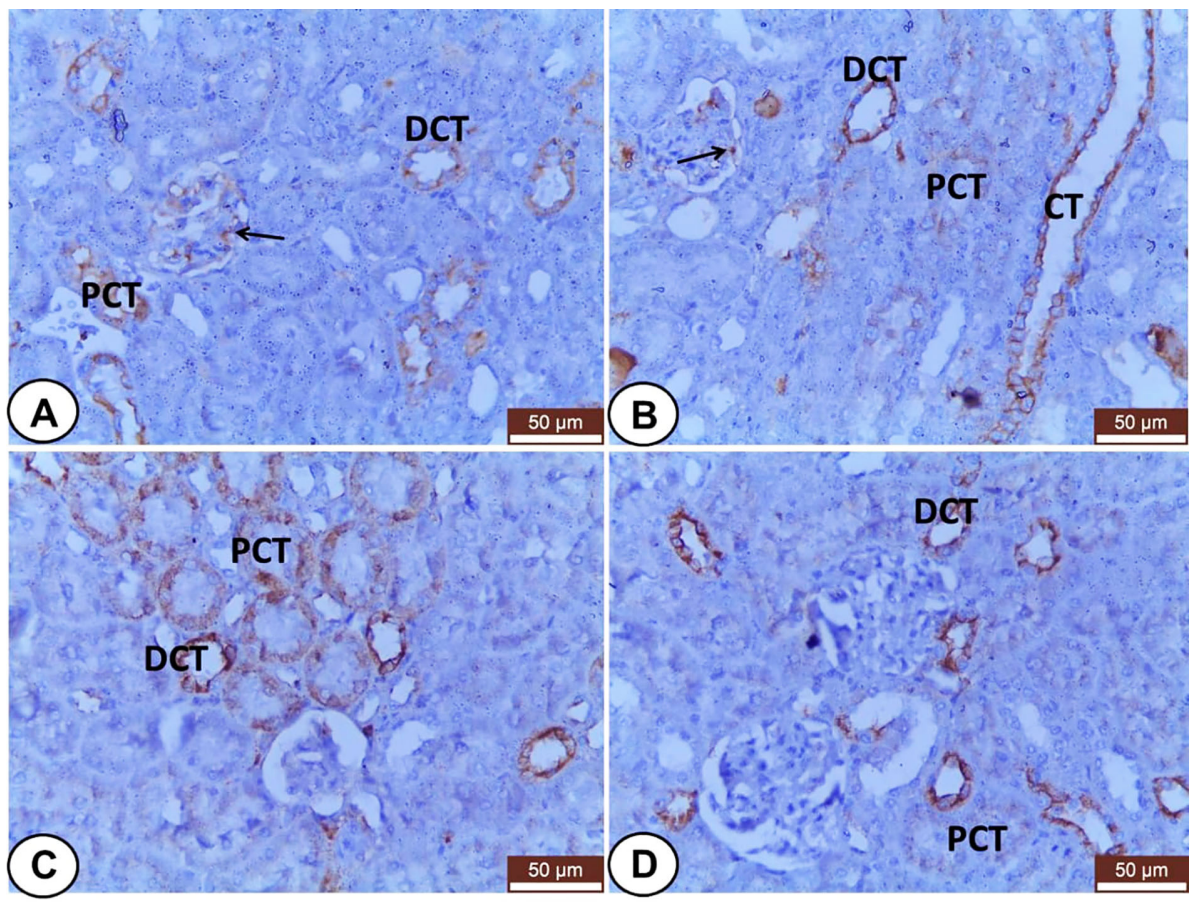

FIGURE 6 | Immunohistochemical staining of CK18 in renal sections from all examined groups. (A, B) Control and LC groups showed weak to moderate cytoplasmic immunostainings in the visceral cells layer of Bowman's capsule (thin arrow) as well as the cells of different segments of renal tubules; proximal convoluted (PCT), distal convoluted (DCT), and collecting (CT) tubules. (C) CP group revealed overexpression of CK18 in the epithelial cells of renal tubules mainly proximal convoluted (PCT) and few distal convoluted (DCT) tubules. (D) LC+CP group displayed lower expression of CK18 in PCT and DCT compared with CP group. Scale bars $=50 \mu \mathrm{m}$.

impaired (Jia et al., 2018; Farid et al., 2019; Fadl et al., 2020). In this work, CP-induced hepatotoxicity was evidenced by significant alternation in serum liver enzymes (AST, ALT, and ALP). This result may be attributed to the metabolism of CP. Mohamed and Badawy (2019) reported CP is significantly taken up by the liver and accumulated in the hepatocyte, causing its damage leading to an increase of the liver enzymes activities. In addition, CP elevates creatinine and urea levels, which are confirmed by Sadeghi et al. (2020) and indicate nephrotoxicity induced by CP. On the other hand, Cayir et al. (2009) attributed the hepatotoxicity and nephrotoxicity induced by CP to the free radical generation in the renal and hepatic cells results in lipid peroxidation and oxidative stress that responsible for cellular damage.

Cisplatin administration produced a significant decrease in the total proteins and albumin, this result is supported by the result of Abuzinadah and Ahmad (2020). The above-mentioned results indicate disturbances in protein metabolism induced by $\mathrm{CP}$ intoxication due to a reduction in protein synthesis, following liver damage and alteration of functional integrity in the kidney leading to proteinuria, so, their plasma level decreases in hepatotoxic/nephrotoxic conditions (Sen et al., 2013).

Concerning oxidative stress/antioxidant parameters, the results of these parameters in the $\mathrm{CP}$ treated group is compatible with El-Shitany and Eid (2017) and Abd El-Kader and Taha, 2020, and Abdel-Razek et al. (2020) in the liver and kidney tissues, respectively. These results own to oxidative stress that is mediated through the generation of reactive oxygen species (ROS) such as superoxide anion and hydroxyl radical and depletion in plasma antioxidant levels (Fadl et al., 2019; Abuzinadah and Ahmad, 2020). So, our results are in harmony with several experimental and clinical studies suggesting that the oxidative stress through the formation of free radicals is one of the mechanisms of CP-induced hepato-renal toxicity (Ibrahim et al., 2018; Neamatallah et al., 2018; Abuzinadah and Ahmad, 2020).

On the other side, LC is a natural nutrient and necessary for the oxidation of fatty acid in the mitochondria to produce ATP (Tunez et al., 2007). So, it has antioxidant properties and plays protective roles against oxidative stress in various tissues, including liver and kidney (Cayir et al., 2009). In this study, the result of the LC+CP treated group is in accordance with Tunez et al. (2007) and Aboubakr et al. (2020), who reported that LC reduces liver enzyme activity, oxidative stress, and damage caused by thioacetamide and tilmicosin in rats. Also, LC can improve the antioxidant enzyme activity, including CAT and $\mathrm{GSH}$, and reduces the MDA concentration in renal tissues in acute renal failure induced by myoglobinuric in rats (Aydogdu et al., 2006). These results were confirmed by the results of histopathology. The ability of LC to significantly improve liver 
and kidney biochemical parameters may be due to its antioxidant effect and its capability to act as a free radical scavenger, leading to the protection of membrane permeability (Augustyniak and Skrzydlewska, 2009). LC prevents oxidative stress and exerts a protective role against mitochondrial toxic agents (Barhwal et al., 2007). Additionally, they reduce the harmful effects of free fatty acids by enabling $\beta$-oxidation (Furuno et al., 2001).

The histological and immunohistochemical observations of the current study are in harmony and confirmed the alterations of the biochemical and oxidant/antioxidant parameters among the experimental groups. Several histological changes in the liver among CP treated group were noted as recently mentioned by Abuzinadah and Ahmad (2020). The central vein and sinusoidal dilatation and congestion are in accordance with Cagin et al. (2015) and Omar et al. (2016). Also, swelling of hepatocytes, hydropic degeneration, and prominence of Kupffer cells are demonstrated in similarity to El-Shitany and Eid (2017) and Neamatallah et al. (2018). In addition, fatty infiltration with signet ring appearance in some hepatocytes was seen as noted by Omar et al. (2016) and El-Shitany and Eid (2017). Otherwise, the pretreatment of CP treated rats with LC can potentially protect the liver against CP-induced histological changes and significantly improve and normalize liver histology that represents by almost normal hepatocytes and sinusoids, but with mild congested central vein with regression of the fatty changes. These findings are similar to El-Shitany and Eid (2017), indicating that LC can attenuate the hepatotoxic effect of CP (Cayir et al., 2009).

Like the recent finding of Abd El-Kader and Taha (2020); Abdel-Razek et al. (2020) and Sadeghi et al. (2020), the current study exhibited many distinguishing degenerative changes in the kidney of the CP group including degeneration and desquamation of the tubular epithelium, congestion, and dilatation of interstitial blood vessels and capillaries as reported by Neamatallah et al. (2018). Moreover, the presence of eosinophilic hyaline casts in some renal tubules agrees with Abd El-Kader and Taha (2020) and Abdel-Razek et al. (2020). Additionally, the deformity of some glomeruli with a widening of glomerular spaces was detected in accordance with Abd El-Kader and Taha (2020). On the other hand, LC administration ameliorated the histological effects of $\mathrm{CP}$ on the kidney, but with mild histological findings evidenced by tubular injury in some renal tubules, and minimal interstitial congestion. This finding confirmed that LC could attenuate the nephrotoxic effect of CP (Yürekli et al., 2011).

The current study focused on immunohistochemical localization of VIM and CK18 in hepato-renal specimens since VIM and CK18 expressions in the liver and kidney had provided a valuable insight into their microanatomy in both healthy and diseased conditions. A co-expression of VIM and CK in areas of damaged tissues was reported (Moll et al., 1991; Stefanovic et al., 1996).

Concerning VIM protein, it has been linked with several pathophysiological conditions such as cancer, rheumatoid arthritis, and HIV (Danielsson et al., 2018).

The detectable VIM in hepatic sinusoids of the present study confirmed the report of Evans (1998) where VIM is widely expressed IF proteins in endothelial cells and fibroblasts. According to Wang et al. (2017), VIM expression in the hepatic sinusoids may reflect its regulatory role of hepatic sinusoidal flow. At the beginning of this decade, both Golbar et al. (2011) and Aiad et al. (2012) regarded the sinusoidal VIM expression as hepatic stellate cells (HSCs), which are normally localized at the space of Disse. Moreover, Kupffer cells in the current study were VIM positive as mentioned by Sharifi et al. (2000) and Golbar et al. (2011). After the injection of CP, an overexpression of VIM in the liver was demonstrated in similarity to the lipopolysaccharide intoxicated liver (Lee et al., 2014). The numbers of VIM positive Kupffer cells were increased (Golbar et al., 2011; Aiad et al., 2012), and some individual hepatocytes became VIM positive (Aiad et al., 2012). As well as, sinusoidal VIM expression was increased in response to $\mathrm{CP}$ toxicity where HSCs are activated into myofibroblasts, which characterize by higher VIM expression and more secretion of the extracellular matrix so, they consider as the major contributor to hepatic fibrosis (Shang et al., 2018).

In the normal and diseased kidney, VIM is abundantly present in glomerular mesangial and epithelial cells (Gonlusen et al., 2001; Matos et al., 2007). Our study revealed VIM expression in the glomeruli of all examined rats confirming the above-mentioned data. In addition, VIM was expressed in the interstitial blood vessels and fibroblasts of all examined rats that agree with Stefanovic et al. (1996) and Sen et al. (2010) suggesting that the pivotal regulating role of the renal interstitium for vessels-tubules interaction as well as its involvement in the etiology of renal pathologies (Becker and Hewitson, 1997). It was interesting that the current results revealed undetectable VIM in the renal tubular epithelium of the control rats that agree with Skinnider et al. (2005) and Sen et al. (2010). Otherwise, the overexpression of VIM in renal tubules and interstitial tissue of the CP group was noted may be attributed to glomerulonephritis or tubule-interstitial injury (Gonlusen et al., 2001; Matos et al., 2007), respectively.

Cytokeratins of hepato-renal tissues increase in response to toxicants, oxidative stress, inflammation, and other damaging insults (Toivola et al., 2010). Hepatocytes, as one of the epithelial cells of the liver, have been known to express CKs (Ku et al., 2007). The hepatocytes of both control and LC treated rats showed faint CK18 at the cell periphery forming reticular staining patterns that agree with Zatloukal et al. (2004). Upon injury by $\mathrm{CP}$, the intoxicated hepatocytes exhibited strong, dense, and clumped CK18 staining that agrees with Omary and Coulumbe (2004). Moreover, immunohistochemical overexpression of CK18 in hepatocellular carcinoma was noted (Sawan, 2009). These findings point to the structural role of CK18 to hepatocytes providing them mechanical stability. Another role of CK18 is a target and modulator of toxic stress (Zatloukal et al., 2004) therefore; the current study reported that the CK18 expression was significantly upregulated by oxidative stress induced by CP. That confirmed CK-18 levels as a predictor for hepatitis progression (Yang et al., 2015).

Cytokeratins are often used as disease markers in renal pathology and experimental research (Djudjaj et al., 2016). 
Expression of CK18 in the parietal cells of Bowman's capsule as well as the different segments of renal tubules of the normal rats agree with the finding of Stefanovic et al. (1996) and Djudjaj et al. (2016). CK18 staining was stronger in the collecting ducts as mentioned by Sen et al. (2010). Like Snider (2016), our finding showed a pronounced overexpression of CK18 in the damaged renal tubules in CP treated group indicating that CK18 was upregulated by tubular injury. Therefore, CK18 can be used as a marker and regulator of renal tubular epithelial injury (Djudjaj et al., 2016).

It was noteworthy to record that the pretreatment of LC could decrease expressions of VIM and CK18 in hepato-renal tissues compared with $\mathrm{CP}$ group indicating the ameliorative role of LC against CP toxicity, especially in restoring the organization of IFs.

\section{CONCLUSIONS}

Cisplatin induced hepato-renal toxicity associated with oxidative damage, lipid peroxidation, histological changes, and disorganization of the cytoskeleton IFs; VIM and CK18. A daily LC treatment at $100 \mathrm{mg} / \mathrm{kg}$ exerts ameliorative effects against $\mathrm{CP}$-induced hepato-renal toxicity. The antioxidant effect of LC was evidenced by the restoration of activities of oxidative/antioxidant markers, histological pictures, and VIM and CK18 organization in hepato-renal tissues. Therefore, this study suggests LC as a supplement for cancer patients under CP treatment.

\section{REFERENCES}

Abd El-Kader, M., and Taha, R. I. (2020). Comparative nephroprotective effects of curcumin and etoricoxib against cisplatin-induced acute kidney injury in rats. Acta Histochem. 122 (4), 151534. doi: 10.1016/j.acthis.2020.151534

Abdel-Daim, M. M., El-Sayed, Y. S., Abd Eldaim, M., and Ibrahim, A. (2017). Nephroprotective efficacy of ceftriaxone against cisplatin-induced subchronic renal fibrosis in rats. N-S. Arch. Pharmacol. 390 (3), 301-309. doi: 10.1007/ s00210-016-1332-5

Abdel-Daim, M. M., Abdel-Rahman, H. G., Dessouki, A. A., El-Far, A. H., Khodeer, D. M., Bin-Jumah, M., et al. (2020). Impact of garlic (Allium sativum) oil on cisplatin-induced hepatorenal biochemical and histopathological alterations in rats. Total Sci. Environ. 710, 136338. doi: 10.1016/j.scitotenv.2019.136338

Abdellatief, S. A., Galal, A. A., Farouk, S. M., and Abdel-Daim, M. M. (2017). Ameliorative effect of parsley oil on cisplatin-induced hepato-cardiotoxicity: a biochemical, histopathological, and immunohistochemical study. Biomed. Pharmacoth. 86, 482-491. doi: 10.1016/j.biopha.2016.12.038

Abdel-Razek, E. A., Abo-Youssef, A. M., and Azouz, A. A. (2020). Benzbromarone mitigates cisplatin nephrotoxicity involving enhanced peroxisome proliferatoractivated receptor-alpha (PPAR- $\alpha$ ) expression. Life Sci. 243, 117272. doi: 10.1016/j.lfs.2020.117272

Abo-Elmaaty, A. M., Behairy, A., El-Naseery, N. I., and Abdel-Daim, M. M. (2020). The protective efficacy of vitamin $\mathrm{E}$ and cod liver oil against cisplatininduced acute kidney injury in rats. Environ. Sci. Pollut. Res. 1-15. doi: 10.1007/s11356-020-10351-9

Aboubakr, M., Elsayd, F., Soliman, A., Fadl, S. E., El-Shafey, A., and Abdelhiee, E. Y. (2020). 1-Carnitine and vitamin E ameliorate cardiotoxicity induced by tilmicosin in rats. Environ. Sci. Pollut. Res. 27 (18), 23026-23034. doi: 10.1007/ s11356-020-08919-6

Abuzinadah, M. F., and Ahmad, A. (2020). Pharmacological studies on the efficacy of a thymoquinone-containing novel polyherbal formulation against cisplatin-

\section{DATA AVAILABILITY STATEMENT}

The raw data supporting the conclusions of this article will be made available by the authors, without undue reservation.

\section{ETHICS STATEMENT}

The animal study was reviewed and approved by Faculty of Veterinary Medicine, Benha University, Egypt.

\section{AUTHOR CONTRIBUTIONS}

All authors contributed equally to this article. SA and MA-D funding acquisition and project administration and assisted in writing and editing the manuscript with other authors.

\section{FUNDING}

This work was funded by Researchers Supporting Project number (RSP 2020/27), King Saud University, Riyadh, Saudi Arabia.

\section{ACKNOWLEDGMENTS}

The authors are grateful to King Saud University, Riyadh, Saudi Arabia, for funding this work through Researchers Supporting Project number (RSP 2020/27).

induced hepatorenal toxicity in rats. J. Food Biochem. 44 (2), e13131. doi: $10.1111 /$ jfbc. 13131

Adeyemi, O. O., Ishola, I. O., and Ajani, I. D. (2017). Citrullus colocynthis Linn. Fruit extract ameliorates cisplatin-induced hepato-renal toxicity in rats. J. Complement. Integr. Med. 15 (1). doi: 10.1515/jcim-2017-0086

Aebi, H. (1984). Catalase in vitro. Method. Enzymol. 105, 121-126. doi: 10.1016/ S0076-6879(84)05016-3

Aiad, H. A., Kandil, M. A., Samaka, R. M., Sultan, M. M., Badr, M. T., and Nada, G. E. (2012). The role of CK7, Ki-67, CD34 and vimentin in the differentiation between biliary atresia and idiopathic neonatal hepatitis in Egyptian cholestatic neonates. Acta Pathol. Microbiol. Immunol. Scand. 120 (7), 529-538. doi: 10.1111/j.1600-0463.2011.02859

Al-Majed, A. A., Sayed-Ahmed, M. M., Al-Yahya, A. A., Aleisa, A. M., Al-Rejaie, S. S., and Al-Shabanah, O. A. (2006). Propionyl-L-carnitine prevents the progression of cisplatin-induced cardiomyopathy in a carnitine-depleted rat model. Pharmacol. Res. 53, 278-286. doi: 10.1016/j.phrs.2005.12.005

Augustyniak, A., and Skrzydlewska, E. (2009). L-Carnitine in the lipid and protein protection against ethanol-induced oxidative stress. Alcohol 43 (3), 217-223. doi: 10.1016/j.alcohol.2008.12.005

Avsar, U. Z., Avsar, U., Aydin, A., Yayla, M., Ozturkkaragoz, B., Un, H., et al. (2014). L-carnitine alleviates sciatic nerve crush injury in rats: functional and electron microscopy assessments. Neural Regen. Res. 9 (10), 1020-1024. doi: 10.4103/1673-5374.133163

Aydogdu, N., Atmaca, G., Yalcin, O., Taskiran, R., Tastekin, E., and Kaymak, K. (2006). Protective effects of L-carnitine on myoglobinuric acute renal failure in rats. Clin. Exp. Pharmacol. Physiol. 33 (1-2), 119-124. doi: 10.1111/j.14401681.2006.04336.x

Bancroft, J. D., Layton, C., and Suvarna, S. K. (2013). Bancroft's Theory and Practice of Histological Techniques (Amsterdam, the Netherlands: Elsevier).

Barhwal, K., Singh, S. B., Hota, S. K., Jayalakshmi, K., and Ilavazhagan, G. (2007). Acetyl-L-carnitine ameliorates hypobaric hypoxic impairment and spatial 
memory deficits in rats. Eur. J. Pharmacol. 570, 97-107. doi: 10.1016/ j.ejphar.2007.05.063

Bartels, H., Böhmer, M., and Heierli, C. (1972). Serum creatinine determination without protein precipitation. Clin. Chim. Acta 37, 193-197. doi: 10.1016/ 0009-8981(72)90432-9

Becker, G. J., and Hewitson, T. D. (1997). The interstitium in renal Disease. J. Intern. Med. 242 (2), 93-97. doi: 10.1046/j.1365-2796.1997.00207.x

Bremer, J. (1983). Carnitine-metabolism, functions. Physiol. Rev. 63, 1420-1480. doi: 10.1152/physrev.1983.63.4.1420

Cagin, Y. F., Erdogan, M. A., Sahin, N., Parlakpinar, H., Yatayan, A., Apolat, A., et al. (2015). Protective Effects of Apocynin on Cisplatin-induced Hepatotoxicity In Rats. Arch. Med. Res. 46 (7), 517-526. doi: 10.1016/ j.arcmed.2015.08.005

Cayir, K., Karadeniz, A., Yildirim, A., Kalkan, Y., Karakoc, A., Keles, M., et al. (2009). Protective effect of L-carnitine against cisplatin-induced liver and kidney oxidant injury in rats. Cent. Eur. J. Med. 4 (2), 184-191. doi: 10.2478/s11536-009-0021-x

Cetinkaya, A., Bulbuloglu, E., Kantarceken, B., Ciralik, H., Kurutas, E. B., Buyukbese, M. A., et al. (2006). Effects of L-carnitine on oxidant/antioxidant status in acetic acid-induced colitis. Dig. Dis. Sci. 51, 488-494. doi: 10.1007/ s10620-006-3160-9

Coulombe, J. J., and Favreau, L. A. (1963). new simple semimicro method for colorimetric determination of urea. Clin. Chem. 9, 102-108. doi: 10.1093/ clinchem/9.1.102

Danielsson, F., Peterson, M. K., Araújo, H. C., Lautenschläger, F., and Gad, A. K. (2018). Vimentin Diversity in Health and Disease. Cells 7, 147. doi: 10.3390/ cells7100147

Djudjaj, S., Papasotiriou, M., Bulow, R. D., Wagnerova, A., Lindenmeyer, M. T., Cohen, C. D., et al. (2016). Keratins are novel markers of renal epithelial cell injury. Kidney Int. 89, 792-808. doi: 10.1016/j.kint.2015.10.015

Doumas, B. T., Bayse, D. D., Carter, R. J., Peters, T., and Schaffer, R. A. (1981). Candidate reference method for determination of total protein in serum. I. Development and validation. Clin. Chem. 27 (10), 1642-1650. doi: 10.1093/ clinchem/27.10.1642

Doumas, B. T., Watson, W. A., and Biggs, H. G. (1971). Albumin standards and the measurement of serum albumin with bromcresol green. Clin. Chim. Acta 31 (1), 87-96. doi: 10.1016/0009-8981(71)90365-2

El-Shitany, N. A., and Eid, B. (2017). Proanthocyanidin protects against cisplatininduced oxidative liver damage through inhibition of inflammation and NF-

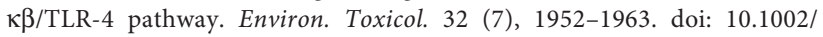
tox.22418

Evans, R. M., and Simpkins, H. (1998). Cisplatin Induced Intermediate Filament Reorganization and Altered Mitochondrial Function in 3T3 Cells and DrugSensitive and Resistant Walker 256 Cells. Exp. Cell Res. 245 (1), 69-78. doi: 10.1006/excr.1998.4250

Evans, R. M. (1998). Vimentin: the conundrum of the intermediate filament gene family. Bioessays 20, 79-86. doi: 10.1002/(SICI)1521-1878(199801)20:1<79:: AID-BIES11>3.0.CO;2-5

Fadl, S. E., El-Habashi, N., Gad, D. M., Elkassas, W. M., Elbialy, Z. I., Abdelhady, D. H., et al. (2019). Effect of adding Dunaliella algae to fish diet on lead acetate toxicity and gene expression in the liver of Nile tilapia. Toxin Rev. 1-17. doi: 10.1080/15569543.2019.1652652

Fadl, S. E., El-Shenawy, A. M., Gad, D. M., El Daysty, E. M., El-Sheshtawy, H. S., and Abdo, W. S. (2020). Trial for reduction of Ochratoxin A residues in fish feed by using nano particles of hydrated sodium aluminum silicates (NPsHSCAS) and copper oxide. Toxicon. 184, 1-9. doi: 10.1016/ j.toxicon.2020.05.014

Farid, A. S., El Shemy, M. A., Nafie, E., Hegazy, A. M., and Abdelhiee, E. Y. (2019). Anti-inflammatory, anti-oxidant and hepatoprotective effects of lactoferrin in rats. Drug Chem. Toxicol. 1-8. doi: 10.1080/01480545.2019.1585868

Furuno, T., Kanno, T., Arita, K., Asami, M., Utsumi, T., Doi, Y., et al. (2001). Roles of long chain fatty acids and carnitine in mitochondrial membrane permeability transition. Biochem. Pharmacol. 62 (8), 1037-1046. doi: 10.1016/S0006-2952(01)00745-6

Golbar, H. M., Izawa, T., Yano, R., Ichikawa, C., Sawamoto, O., Kuwamura, M., et al. (2011). Immunohistochemical Characterization of Macrophages and Myofibroblasts in $\alpha$-Naphthylisothiocyanate (ANIT)-Induced Bile Duct
Injury and Subsequent Fibrogenesis in Rats. Toxicol. Pathol. 39, 795-808. doi: $10.1177 / 0192623311413790$

Gonlusen, G., Ergin, M., Payda, S., and Tunali, N. (2001). The expression of cytoskeletal proteins ( $\alpha$-SMA, vimentin, desmin) in kidney tissue: A comparison of fetal, normal kidneys, and glomerulonephritis. Int. Urol. Nephrol. 33, 299-305. doi: 10.1023/A:1015226426000

Hwang, D. B., Won, D. H., Shin, Y. S., Kim, S. Y., Kang, B. C., Lim, K. M., et al. (2020). Ccrn4l as a pre-dose marker for prediction of cisplatin-induced hepatotoxicity susceptibility. Free Radic. Biol. Med. 148, 128-139. doi: 10.1016/j.freeradbiomed.2020.01.003

Ibrahim, A., Abd Eldaim, M. A., and Abdel-Daim, M. M. (2016). Nephroprotective effect of bee honey and royal jelly against subchronic cisplatin toxicity in rats. Cytotechnol 68 (4), 1039-1048. doi: 10.1007/s10616015-9860-2

Ibrahim, A., Al-Hizab, F. A., Abushouk, A. I., and Abdel-Daim, M. M. (2018). Nephroprotective effects of benzyl isothiocyanate and resveratrol against cisplatin-induced oxidative stress and inflammation. Front. Pharmacol. 9, 1268. doi: $10.3389 /$ fphar.2018.01268

Jia, Y. N., Lu, H. P., Peng, Y. L., Zhang, B. S., Gong, X. B., Su, J., et al. (2018). Oxyresveratrol prevents lipopolysaccharide/dgalactosamine-induced acute liver injury in mice. Int. Immunopharmacol. 56, 105-112. doi: 10.1016/ j.intimp.2018.01.014

Karwasra, R., Kalra, P., Gupta, Y. K., Saini, D., Kumar, A., and Singh, S. (2016). Antioxidant and anti-inflammatory potential of pomegranaterind extract to ameliorate cisplatin-induced acute kidney injury. Food Funct. 7 (7), 30913101. doi: $10.1039 / \mathrm{C} 6 \mathrm{FO} 00188 \mathrm{~B}$

Ku, N., Zhou, X., Toivola, D. M., and Omary, M. B. (1999). The cytoskeleton of digestive epithelia in health and disease. Am J. Physiol. 277, G1108-G1137. doi: 10.1152/ajpgi.1999.277.6.G1108

Ku, N., Strnad, P., Zhong, B., Tao, G., and Omary, M. B. (2007). Keratins Let Liver Live: Mutations Predispose to Liver Disease and Crosslinking Generates Mallory-Denk Bodies. Hepatol 46 (5), 1639-1649. doi: 10.1002/hep.21976

Lee, S. J., Yoo, J. D., Choi, S. Y., and Kwon, O. (2014). The expression and secretion of vimentin in the progression of non-alcoholic steatohepatitis. BMB Rep. 47 (8), 457-462. doi: 10.5483/BMBRep.2014.47.8.256

Liu, L., Qian, J., Singh, H., Meiers, I., Zhou, X., and Bostwick, D. G. (2007). Immuno-histochemical analysis of chromophobe renal cell carcinoma, renaloncocytoma, and clear cell carcinoma an optimal and practical panelfor differential diagnosis. Arch. Pathol. Lab. Med. 131, 1290-1297. doi: 10.1043/ 1543-2165(2007)131[1290:IAOCRC]2.0.CO;2

Matos, A. C. C., de Franco, M. F., Moura, L. A. R., Moreira, R. F., and PachecoSilva Filho, A. (2007). Vimentin expression is a predictor of renal dysfunction after kidney transplantation. Einstein 5 (2), 153-160.

Meng, H., Fu, G., Shen, J., Shen, K., Xu, Z., Wang, Y., et al. (2017). Ameliorative effect of Daidzein on cisplatin-induced nephrotoxicity in mice via modulation of inflammation, oxidative stress, and cell death. Oxid. Med. Cell. Longev. 2017:3140680. doi: 10.1155/2017/3140680

Miller, R. P., Tadagavadi, R. K., Ramesh, G., and Reeves, W. B. (2010). Mechanisms of cisplatin nephrotoxicity. Toxins 2 (11), 2490-2518. doi: 10.3390/toxins 2112490

Mohamed, H. E., and Badawy, M. M. M. (2019). Modulatory effect of zingerone against cisplatin or $\gamma$-irradiation induced hepatotoxicity by molecular targeting regulation. Appl. Radiat. Isot. 154, 108891. doi: 10.1016/j.apradiso.2019.108891

Moll, R., Hage, C., and Thoenes, W. (1991). Expression of intermediate filament proteins in fetal and adult human kidney: Modulations of intermediate filament patterns during development and in damaged tissue. Lab. Investig. $65,74-86$.

Neamatallah, T., El-Shitany, N. A., Abbas, A. T., Ali, S. S., and Eid, B. G. (2018). Honey protects against cisplatininduced hepatic and renal toxicity through inhibition of NF-אB-mediated COX-2 expression and the oxidative stress dependent BAX/Bcl-2/caspase-3 apoptotic pathway. Food Funct. 9 (7), 37433754. doi: $10.1039 / \mathrm{c} 8$ fo00653a

Ohkawa, H., Ohishi, N., and Yagi, K. (1979). Assay for lipid peroxides in animal tissues by thiobarbituric acid reaction. Anal. Biochem. 95, 351-358. doi: 10.1016/0003-2697(79)90738-3

Omar, H. A., Mohamed, W. R., Arafa, E. A., Shehata, B. A., El Sherbiny, G. A., Arab, H. H., et al. (2016). Hesperidin alleviates cisplatin-induced 
hepatotoxicity in rats without 4 inhibiting its antitumor activity. Pharmacol. Rep. 68 (2), 349-356. doi: 10.1016/j.pharep.2015.09.007

Omary, B., and Coulumbe, P. A. (2004). Intermediate filament cytoskeleton in: Methods in cell biology Vol. 78 (San Diego, CA, USA: Elsevier Academic press), 209.

Qu, X., Gao, H., Tao, L., Zhang, Y., Zhai, J., Sun, J., et al. (2019). Astragaloside IV protects against cisplatin-induced liver and kidney injury via autophagymediated inhibition of NLRP3 in rats. J. Toxicol. Sci. 44 (3), 167-175. doi: $10.2131 /$ jts. 44.167

Reitman, S., and Frankel, S. A. (1957). Colorimetric method for the determination of serum glutamic oxalacetic and glutamic pyruvic transaminases. Am. J. Clin. Pathol. 28 (1), 56-63. doi: 10.1093/ajcp/28.1.56

Sadeghi, H., Mansourian, M., PanahiKokhdan, E., Salehpour, Z., Sadati, I., Abbaszadeh-Goudarzi, K., et al. (2020). Antioxidant and protective effect of Stachys pilifera Benth against nephrotoxicity induced by cisplatin in rats. J. Food Biochem. 44 (5), e13190. doi: 10.1111/jfbc.13190

Sawan, A. S. (2009). The Diagnostic Value of Immunohistochemistry in the Diagnosis of Primary and Secondary Hepatic Carcinomas. J. King Abdulaziz Univ. Med. Sci. 16 (4), 37-48. doi: 10.4197/med.16-4.3

Sedlak, J., and Lindsay, R. H. (1968). Estimation of total, protein-bound, and nonprotein sulfhydryl groups in tissue with Ellman's reagent. Anal. Biochem. 25, 192-205. doi: 10.1016/0003-2697(68)90092-4

Sen, S., Sarsık, B., and Simsir, A. (2010). Immunohistochemical Markers in Renal Tumors and Findings in Non-Tumoral Renal Parenchyma. Turk. J. Pathol. 26 (2), 120-129. doi: 10.5146/tjpath.2010.01008

Sen, S., De, B., Devanna, N., and Chakraborty, R. (2013). Cisplatin induced nephrotoxicity in mice: protective role of Leea asiatica leaves. Renal Fail. 35 (10), 1412-1417. doi: 10.3109/0886022X.2013.829405

Sezen, O., Ertekin, M. V., Demircan, B., Karslıgglu, I., Erdogan, F., Kocer, I., et al. (2008). Vitamin E and L-carnitine, separately or in combination, in the prevention of radiation-induced brain and retinal damages. Neurosurg. Rev. 31, 205-213. doi: 10.1007/s10143-007-0118-0

Shang, L., Hosseini, M., Xiao, L., Kisseleva, T., and Brenner, D. A. (2018). Human hepatic stellate cell isolation and characterization. J. Gastroenterol. 53, 6-17. doi: 10.1007/s00535-017-1404-4

Sharifi, S., Hayek, J., Khettry, U., and Nasser, I. (2000). Immunocytochemical Staining of Kupffer and Endothelial Cells in Fine Needle Aspiration Cytology of Hepatocellular Carcinoma. Acta Cytol. 44 (1), 7-12. doi: 10.1159/000326216

Skinnider, B. F., Folpe, A. L., Hennigar, R. A., Lim, S. D., Cohen, C., Tamboli, P., et al. (2005). Distribution of cytokeratins and vimentin in adult renal neoplasms and normal renal tissue: potential utility of a cytokeratin antibody panel in the differential diagnosis of renal tumors. Am. J. Surg. Pathol. 29, 747-754. doi: 10.1097/01.pas.0000163362.78475.63
Snider, N. T. (2016). Kidney keratins: cytoskeletal stress responders with biomarker potential. Kidney Int. 89, 738-740. doi: 10.1016/j.kint. 2015.12.040

Stefanovic, V., Cukuranovic, R., Dojcinov, D., and Savic, V. (1996). Coexpression of Vimentin and Cytokeratin in Damaged Tubular Epithelia of Kidney in Balkan Nephropathy. Nephron 72, 119-120. doi: 10.1159/000188826

Tietz, N. W., Burtis, C. A., Duncan, P., Ervin, K., Petitclerc, C. J., Rinker, A. D., et al. (1983). A reference method for measurement of alkaline phosphatase activity in human serum. Clin. Chem. 29 (5), 751-761. doi: 10.1093/clinchem/29.5.751

Toivola, D. M., Strnad, P., Habtezion, A., and Omary, M. B. (2010). Intermediate filaments take the heat as stress proteins. Trends Cell Biol. 20, 79-91. doi: 10.1016/j.tcb.2009.11.004

Tunez, I., Munoz, M. C., Medina, F. J., Salcedo, M., Feijóo, M., and Montilla, P. (2007). Comparison of melatonin, vitamin $\mathrm{E}$ and L-carnitine in the treatment of neuro- and hepatotoxicity induced by thioacetamide. Cell Biochem. Funct. 25 (2), 119-127. doi: 10.1002/cbf.1276

Wang, L., Tu, L., Zhang, J., Xu, K., and Qian, W. (2017). Stellate Cell Activation and Imbalanced Expression of TGF- $\beta 1 /$ TGF- $\beta 3$ in Acute Autoimmune Liver Lesions Induced by ConA in Mice. BioMed. Res. Int. 2017, 2540540. doi: $10.1155 / 2017 / 2540540$

Yang, Z. H., Yang, S. X., Qin, C. Z., and Chen, Y. X. (2015). Clinical Values of Elevated Serum Cytokeratin-18 Levels in Hepatitis: A Meta-Analysis. Hepat. Mon. 15 (5), e25328. doi: 10.5812/hepatmon.15(5)2015.25328

Yürekli, Y., Unak, P., Yenisey, C., Ertay, T., Biber Müftüler, F. Z., Medine, E., et al. (2011). L-Carnitine Protection Against Cisplatin Nephrotoxicity In Rats: Comparison with Amifostin Using Quantitative Renal Tc 99m DMSA Uptake. Mol. Imaging Radionucl. Ther. 20 (1), 1-6. doi: 10.4274/MIRT.20.01

Zatloukal, K., Stumptner, C., Fuchsbichler, A., Fickert, P., Lackner, C., Trauner, M., et al. (2004). The keratin cytoskeleton in liver diseases. J. Pathol. 204 (4), 367-376. doi: 10.1002/path.1649

Conflict of Interest: The authors declare that the research was conducted in the absence of any commercial or financial relationships that could be construed as a potential conflict of interest.

Copyright $\odot 2020$ Elkomy, Abdelhiee, Fadl, Emam, Gad, Sallam, Alarif, Abdel-Daim and Aboubakr. This is an open-access article distributed under the terms of the Creative Commons Attribution License (CC BY). The use, distribution or reproduction in other forums is permitted, provided the original author(s) and the copyright owner(s) are credited and that the original publication in this journal is cited, in accordance with accepted academic practice. No use, distribution or reproduction is permitted which does not comply with these terms. 